\title{
Analysis Of Business To Business E-Commerce
}

\author{
Bharti Thakur \\ Jalandhar, Punjab
}

\begin{abstract}
Electronic business is more than just another way to enhance the business practices. B2B e-commerce is paradigm shift influencing both the buyer and supplier. E-business showing tremendous business growth in our country. The massive increase in digital technology has added growth of business and differentiating business model. this study describes the present scenario of electronic business, describe the business portal and analysis the changing trends. The study further examines the strength and weakness of business to business e-commerce and analysis the opportunity and threat of e-business.
\end{abstract}

Keywords: Business to Business e-commerce, B2B software and portal, trends and swot analysis

\section{Introduction:}

E-commerce basic means is electronic commerce that is selling and buying of various information, good and services over an electronic medium like the internet. we are moving to digital technology in which demand realized translate into demand satisfied in nanoseconds. Today majority of business have an online presence and become necessities for many companies to conduct their business online and they continuously think their business in terms of an internet where a wide range of selling and buying occur.

E-commerce smooth or ease the growth of the electronic business by online marketing, online sale, online payment and product service. Doing business online is not mean for online shopping. Online shopping is just part of e-commerce. It includes online stock, online transactions and selling the company asset through online. It can also reduce the cost of assigning the various order and interacting with a wide range of supplier and trading partners. Therefore business to business e-commerce sale is going fast as business to consumer

\section{Objectives of study:}

- To describe the business to business marketing and portal

- To analysis Changing trends in B2B marketing
- The SWOT analysis of B2B marketing

\section{B2B Marketing}

It is buying and selling process take place between two businesses. In B2B the dealer mainly establishes the relationship with the manufacturer, wholesaler and also retailer. In this supply chain mainly occurs more than two companies that are selling the products or goods to an intermediate buyer who then sells the goods to the final customer.

Business to business e-commerce means different thing to different people and companies. to some, it means web-enabled selling and to some it means middleware. We can say that B2B mean to use of innovative technology to build the global relationship with customers or it simply means doing business on the internet. With e-commerce business customers demand more choices and convenience, the cost is drastically lower and competition increase in every direction, distribution channel is exploding and startup are bringing established giant to their knees. Bringing business together more information take place in one portal. Electronics, shipping, and warehouse, motor vehicle, agriculture, papers, office products are the leading items in business to business marketing.

the conventional method of doing business and electronic business is explained by example customers walk into automobile dealership and order car. That order is then placed with the manufacturer, manufacturer order the part to supplier and supplier order the raw material of that 
part and then manufacturer create the car. Between these order, paperwork is done. paper request sent to a supplier and send a paper invoice to request the payment. When all the parts are received from supplier and car can be manufactured and then sent to dealer resulting more paper-like invoice and purchase order and this process takes months.

In electronic business use of EDI that is electronic data interchange paperwork is reduced. When that customer order car via the internet that an action is a business event that is captured. Our system must react to this event by performing several tasks instantaneously, logging the event, processing rules bound to such event and moving information to another interesting system

EDI (electronic data interchange) in today technology EDI is most commonly used in business to business e-commerce. It is an exchange of business documents like purchase order and invoice order document in electronic format between two business partners. EDI is used in many industries and high technology service.

\section{Integration is done by two ways in B2B e- commerce}

At data level integration: automation exchange of business documents between business application in procure to pay process

At people level integration: integration between the people in different companies such new vendor registration

Backend information system integration: in this system, all the business database of the vendor are managed and integrate inventory management software because order tends to happen in large quantities and we must ensure that business has inventory.

\section{B2B Software And Portal}

The websites or portal in which e-commerce business occur are user-friendly and allow the buyer to get informed. Supplier company presents its products or service with price, other useful detail like a custom discount. The customer accesses the portal and analyze all offer and place an order or an offer request. regular customers directly send the offer to the desired product via email. In some cases, a registration process occurs and the company asks the customer to create their account for secure access to information related to orders and payment or offer.
Supplier company also doing promotion by product or presentation, online support and providing coupon so on.

Mainly Business to Business e-commerce used OmniChannel strategy to maintain the effective business, these strategies include:

1. The configuration of products: B2B portal always make easy for the customer to search the specific product they want by offering different tools, product filter and configuration.and also update the new product with special description.

2. Customer buying behavior: dealer always consider the buying behaving of customer by highlighting the prioritized the product and provide the feedback option in this way dealer can check the customer behavior regarding their products

3. Avoid channel conflict: clarify all the rules by increasing the quality of products and executing the reorder activities.

B2B e-commerce connected to ERP: to increase the performance of the online store, mainly trader use business logic and data from ERP, this help to avoid complex connection and trading company product catalog automatically update and reduce the possibility of error during order processing. It also increases the accuracy of fill the order and ensure the transparency of information

\section{Examples Of Top India B2b E-Commerce Websites:}

1. mjunction.com: mjunction.com innovative for outcomes, world largest marketplace steel.it is founded in 2001 and offer a wide range of e-selling,e-sourcing,efinancing service. vinaya Verma is the CEO of this websites. The key business area is coal junction, metal junction, and value junction.

2. Indiamart.com: indiamart online channel mainly focuses on providing a platform to Small \& Medium Enterprises, large enterprises it is Founded in 1996, the company's mission is 'to make doing business easy'. This channel announced its Series C funding in March 2016. many brands are connected with indiamart for secure payment structure. 
3. Exportersindia.com : largest searchable B2B marketplace, it is founded in 1997 and provide platforms to various business entrepreneurs to interact in the global market. It provides free registration to companies and updates all information regarding tradeshow. Many businesses are connected with this portal.

4. B2B.sulekha.com: sulekha.com website designed for property need, buying and selling the property, information on localities and broker and rental.it is classified as real estate and other residential flats, apartment etc. Satya Prabhakar is the CEO of this websites.

5. jimtrade.com: it provides the complete information on Indian products and suppliers for buyers. JimTrade is the number one destination for buyers to source Indian products and for Indian sellers to find trade opportunities and promote their businesses online.

\section{Benefit of using B2B PORTAL}

1. Customer loyalty increased using $b 2 b$ portal by providing secure payment and quick service to customers

2. All the products and services are automatically updated in real-time basis

3. In this portal large number of products with their characteristics are present which is impossible in offline

4. Some company provide video demonstration and other information to improve sale process

5. The B2B portal also provides the order status information.

\section{Trends In Business To Business E-Commerce Market}

B2B e-commerce is global estimate $\$ 1.25$ trillion. today B2B organization are adopted the online channel and they are now focusing on how to increase the revenue. Market research B2B ecommerce industry in India to grow 2.5 times to touch Rs 45 lakh crore by 2020 . More and more organization investing in online channel to present their product portfolio, product specification, catalogs customer review etc. many companies are starting up by providing the incentives model like a discount, coupon. In India, more and more company are investing in the online marketplace to represent their company brand value and attract the wide range of audience.

In the upcoming year, 2018-2019 B2B companies listen to the customer and take action to improve their business by developing strategy that gives omnichannel customer experience and the coming year will be winning time for the $\mathrm{B} 2 \mathrm{~B}$ retailer.

- With possibilities of cognitive technologies, the company gathers the more personalized data about their customer. 94\% retail executives already planned to invest in cognitive technology in future.

- Many e-commerce platforms are completely independent of ERP, order management and inventory management system and result in losing a huge amount of data. This year online store integration offers an automated replenishment and enable B2B company to synchronize the ordering process across different channel

- Many B2B portals will be a shift to a self-service portal like Amazon. To access the app based portal, this will lower the overall cost of sale activities.it also provides better customer service, allow them to focus on customer concern, it helps to attract the new customer with convincing and existing customer become more loyal.

- In 2018, B2B seller integrate other business software to create B2B omnichannel experiences, it will benefit to interact with seller in multiple channels

- Shift to mobile is key trends for B2B marketing, a new business using a mobile device to reach the customer, the majority of B2B businesses have mobile sites and mobile app. For some industry having mobile app wouldn't be necessary but in reality, all should have mobile responsible sites.

- The company using account-based marketing $\mathrm{ABM}$ and work closely with their sale team to identify prospect and message to buy a team at the targeted market. It can improve the alignment between sales and marketing team.

- More trading company shift their focus towards social media to communicate with potential prospect, mainly LINKEDIN is expected to outperform social channel for B2B business

- Content marketing has been popular techniques to acquire lead in B2B marketing. Business will need to do research in a different stage of customer life- 
cycle. Content marketing is effective for B2B business to aware the potential customer about best practices for their industry.

\section{Swot Analysis}

\section{Strength:}

- Brand loyalty is higher than B2C: in business to business e-commerce customer has more loyal because they follow particular brand like Tata steel customer mainly prefer the Tata steel products

- Long-term relationship: B2B customer has maintained the long-term relationship with dealer

- Catalogue personalization: real-time customer catalog view to personalize allowable products for customers, contact, brand etc.

- Real-time inventory information: clearly communicate the real-time inventory information relating to stock and forward order and back order to certain customers

- Automatically scheduled order: allow automatic scheduling of repeat order where customer have auto replenishment requirements

\section{WEAKNESS:}

- Limited market: in B2B market trading between business, in this, there a small number of the buyer rather than million of a potential customer for consumer products.

- Long purchase decision: due to multiple stakeholders and decision maker, customer decision maker can be stretch out for a month.

- Sale process: in B2B sale process is considered complex. It a number of meetings and paper works. High cost involved in B2B business when a large number of the unit is purchased. Sale of Expensive machines or software impacts the performance of thousands of employees.

\section{Opportunity:}

- Maintain the high quality: due to an increase of competition, the business must need to maintain the high quality of product to retain the customers.

- Maintain international standard: in case of international trade, business maintains the international standard like patent, trademark in order to attract the global customers.
- Changing trends: B2B e-commerce changes their working trends on yearly basis and updates their technology and software to meet the customer changing demand.

- Focus on products and brand: B2B business focus on their products, they update their products and present their different marketing tools like filter and custom discount. And business must keep their brand high by doing a various promotion like arranging and participate in various trade shows in different countries.

\section{THREATS:}

- Change in environment and government policies: the B2B company has major threat is a change in external environment and government rules and regulation like a change in tax structure.

- Privacy concern: every B2B portal have to fear about hacking the websites. They must ensure to maintain the privacy and keep the customer record safe.

- In international trade, many risks are occurring that is a delivery risk and political risk these risk may affect the business relationship between buyer and seller.

\section{Conclusion:}

Business to Business e-commerce is important to our life nowadays. As generation evolve and technology develop this business has great impact. Many companies have benefited from having their own e-commerce sites. It is not about selling physical goods and also provide a flexible solution to the customer. Now a days B2B business turning into social media which can raise the company profile and encourage the sales of products. With the increase in technology, B2B e-commerce develops globally by doing international trade. By using websites company reach the other companies and share their data and information. Many businesses participate in different trade show and promote their products. The swot analysis can be performed because to evaluate the opportunity for the different business across the world. 


\section{Reference}

1. https://www.entrepreneur.com/article/304 179

2. https://www.mavenecommerce.com/ecom merce/top-3-b2b-ecommerce-trends-willshape-2018/

3. http://indianonlineseller.com/2016/08/6business-to-business-b2b-onlinemarketplaces-in-india-worth-exploring/

4. https://www.linkedin.com/pulse/futureb2b-e-commerce-india-ashley-babu

5. https://retail.economictimes.indiatimes.co $\mathrm{m} /$ re-tales/trends-that-will-reshapeindian-e-commerce-in-2018/2767

6. https://ecommerceone.wordpress.com/201 5/01/02/b2b-ecommerce-in-india-andtheir-growing-trends/

7. https://virtocommerce.com/glossary/whatis-b2b-ecommerce

8. https://www.seniorsoftware.ro/en/erp/wha t-is-b2b-e-commerce/

9. http://ecommerceandb2b.com/b2b-ecommerce-transactions-shape-channelsp1/

\section{Author Profile}

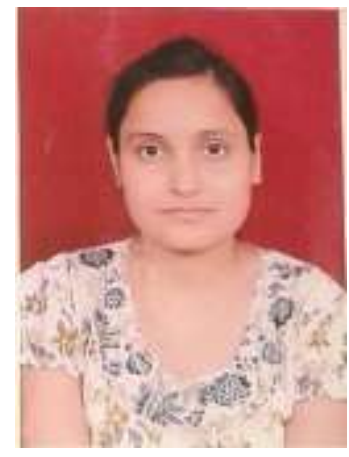

I Bharti thakur received Bachelor degree in electronics and communication engineering from punjab technical university in 2014 and Master Degree in MBA guru nanak dev university in 2017. This is my first paper. I did various studies in this topic. 